Voluntaris einer weitergehenden Betrachtung unterzogen werden. Als Fördergeber möchte das BMZ ein Umfeld schaffen, in dem auch offen über weniger erfolgreiche Erfahrungen und Entwicklungen geredet wird. Nur das ermöglicht uns, gemeinsam voneinander zu lernen. Ich wünsche mir, dass Voluntaris die Analyse und den Austausch über die Entwicklungen rund um entwicklungspolitische Freiwilligendienste begleitet und vorantreibt.

Zum Start wünsche ich der Zeitschrift viel Erfolg und eine breite Leserinnen- und Leserschaft!

\title{
Bundesnetzwerk Bürgerschaftliches Engagement (BBE)
}

\author{
PD Dr. Ansgar Klein
}

Geschäftsführer des Bundesnetzwerks Bürgerschaftliches Engagement ansgar.klein@b-b-e.de|www.b-b-e.de

Im Mai 2013 startet die neue Fachzeitschrift Voluntaris. Sie kommt zur rechten Zeit! Niemals zuvor haben die Freiwilligendienste in Deutschland so große Bedeutung gehabt. Niemals zuvor gab es so viele Teilnehmer und

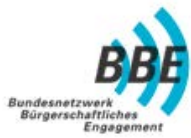
ein so großes Angebotsfeld an Freiwilligendiensten. Und niemals zuvor bestand - nach Gründung des neuen Bundesfreiwilligendienstes und der Umwidmung des ehemaligen Bundesamtes für Zivildienst zum neuen Bundesamt für Familie und zivilgesellschaftliche Aufgaben (,BAFzA“) - so viel Gesprächs- und Diskursbedarf.

Voluntaris hat vor diesem Hintergrund die große Chance und Aufgabe, die bestehenden Fachdiskurse rund um die Freiwilligendienste ebenso aufzunehmen wie die praktischen Erfahrungen derer, die einen der vielen Dienste absolviert haben, zu berichten und auszuwerten.

Folgende Themen werden in einer neuen Fachzeitschrift zu Freiwilligendiensten insbesondere erwartet: 
- Entwicklung der Tätigkeitsprofile in den Freiwilligendiensten im Lichte ihres Auftrages als zivilgesellschaftliche Lerndienste und Bewertung der Arbeitsmarktneutralität

- Qualität des bestehenden Freiwilligenmanagements und der Betreuung in den Einrichtungen

- Qualität und Konzeptionen der pädagogischen Begleitung

- Rolle der Träger und des BAFzA

- neue Modellprojekte

- Freiwilligendienste im Feld der Rettungs- und Hilfsdienste

- Kooperation von Freiwilligendiensten mit der allgemeinen Engagementförderung etwa seitens Freiwilligenagenturen und zentren, Seniorenbüros, Selbsthilfekontaktstellen u. a.

- Freiwilligendienste und Arbeitsmarkt- und Beschäftigungspolitik

- Rechtsentwicklungen und Verwaltungspraxis

- Reform und Konzeptdebatten

- Anerkennungskultur

- Evaluationen

- Verhältnis von Vollzeitdiensten zu zeitintensiven Engagementformen wie FDaG, Telefonseelsorge, Hospiz u. a.

- die besonderen Bedarfe der über 27-jährigen Teilnehmer im neuen Bundesfreiwilligendienst

Zudem sollte eine Zeitschrift für Freiwilligendienste die zunehmend undurchschaubare Vielfalt der Angebote überschaubar und nachvollziehbar darstellen und beleuchten:

Die etablierten Jugendfreiwilligendienste FSJ, FÖJ und ungeregelte internationale Freiwilligendienste sowie die hier bereits vorliegenden Erfahrungen mit Modellprojekten, etwa FSJKultur, FSJ Politik

- weltwärts

- kulturweit

- weitere, etwa auch den Europäischen Freiwilligendienst

- neue Modellprojekte!

- der neue Bundesfreiwilligendienst

- Serviceangebote für Freiwilligendienst-Teilnehmer und Träger

- Selbstorganisationen von Teilnehmern der Freiwilligendienste und deren Aktivitäten 
Das Bundesnetzwerk Bürgerschaftliches Engagement (BBE) führt seit zehn Jahren in seiner Arbeitsgruppe „Freiwilligendienste“ die angesprochene Fachdebatte im Dialog von Praxis, Politik und Wissenschaft. Dort beteiligen sich Träger, Bund, Länder und Kommunen, Unternehmen und Gewerkschaften und die Wissenschaft an den Diskussionen. Die oben dargestellte Agenda entstammt diesen langjährigen Diskussionen.

Das BBE wird sich gerne an den Diskussionen in der neuen Fachzeitschrift Voluntaris beteiligen und wünscht ihr einen guten Start!

\section{Bundessprecher des Freiwilligen Ökologischen Jahres (FÖJ)}

\section{Crispin Gabriel Deppe, Ole Fabricius, Hanin Ibrahim, Johannes Mann \& Eva-Maria Meckel}

Bundessprecherinnen und -sprecher des FÖJ des Jahrgangs 2012/13

Bundessprecher@foej.net $\mid$ www.blog.foej.net

Zwischen August und September letzten Jahres starteten ca. 2900 Jugendliche deutschlandweit ihr Freiwilliges Ökologisches Jahr (FÖJ). Inzwischen sind alle Delegierten gewählt, Arbeitskreise gebildet, Aufgaben verteilt und die ersten Ideen

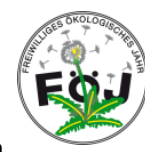
und Aktionen wurden und werden bereits umgesetzt. Das FÖJ ist bis jetzt der einzige Jugendfreiwilligendienst, in dem es ein demokratisches Sprechersystem gibt. Neben Bildung für nachhaltige Entwicklung wird ein Hauptaugenmerk auf Partizipation gelegt. In anderen Freiwilligendiensten ist es dadurch schwerer, Interessen, Forderungen und Wünsche zu bündeln und diesen eine Stimme zu verleihen. Als Bundessprecher des FÖJ begrüßen wir das Entstehen von Voluntaris sehr.

Wir würden es befürworten, wenn auch in anderen Freiwilligendiensten die Verankerung eines Sprechersystems gefördert würde, damit auch diese repräsentativ an einer solchen Zeitschrift teilhaben und ihren Ideen darin Ausdruck verleihen könnten. Je stärker die Freiwilligendienste, Institutionen und Medien zusammen arbeiten, desto effektiver können wir gemeinsam 